\title{
Resting-state functional connectivity of the amygdala and longitudinal changes in depression severity in adolescent depression
}

Colm G. Connolly, PhD 1‡; Tiffany C. Ho, PhD 1,2; Eva Henje Blom, MD, PhD 1,3; Kaja Z. LeWinn, ScD 1; Matthew D. Sacchet, ScB 1,2,4; Olga Tymofiyeva, PhD 5; Alan N.

Simmons, PhD 6,7; Tony T. Yang, MD, PhD ${ }^{1}$

${ }^{1}$ Department of Psychiatry, Division of Child and Adolescent Psychiatry, and Weill Institute for Neurosciences, University of California, San Francisco, 401 Parnassus Avenue, San Francisco, CA, USA.

2 Department of Psychology, Stanford University, Stanford, CA, USA.

${ }^{3}$ Department of Clinical Neuroscience, Karolinska Institutet, Stockholm, Sweden

${ }^{4}$ Neurosciences Program, Stanford University, Stanford, CA, USA.

5 Department of Radiology \& Biomedical Imaging, University of California, San Francisco, 1700 4th St., San Francisco, CA, USA.

6 Department of Psychiatry, University of California, San Diego, 9500 Gilman Dr., La Jolla, CA, USA.

7 Veterans Affairs San Diego Health Care System, La Jolla, CA, USA.

‡ Corresponding author: Department of Psychiatry, Division of Child and Adolescent Psychiatry, and Weill Institute for Neurosciences, University of California, San Francisco, 401 Parnassus Avenue, San Francisco, CA, USA. Email: colm.connolly@ucsf.edu 


\section{Abstract}

\section{Background}

The incidence of major depressive disorder (MDD) rises during adolescence, yet the neural mechanisms of MDD during this key developmental period are unclear. Altered amygdala resting-state functional connectivity (RSFC) has been associated with both adolescent and adult MDD, as well as symptom improvement in response to treatment in adults. However, no study to date has examined whether amygdala RSFC is associated with changes in depressive symptom severity in adolescents.

\section{Method}

We examined group differences in amygdala RSFC between medication-naïve depressed adolescents $(\mathrm{N}=48)$ and well-matched healthy controls $(\mathrm{N}=53)$ crosssectionally. We then longitudinally examined whether baseline amygdala RSFC was associated with change in depression symptoms three months later in a subset of the MDD group ( $\mathrm{N}=24)$.

\section{Results}

Compared to healthy controls, depressed adolescents showed reduced amygdalabased RSFC with the dorsolateral prefrontal cortex (DLPFC)and the ventromedial prefrontal cortex (VMPFC). Within the depressed group, more positive baseline 
RSFC between the amygdala and insulae was associated with greater reduction in depression symptoms three months later.

\section{Limitations}

Only a subset of depressed participants was assessed at follow-up and treatment type and delivery were not standardized.

\section{Conclusions}

Adolescent depression may be characterized by dysfunction of frontolimbic circuits (amygdala-DLPFC, amygdala-VMPFC) underpinning emotional regulation, whereas those circuits (amygdala-insula) subserving affective integration may index changes in depression symptom severity and may therefore potentially serve as a candidate biomarker for treatment response. Furthermore, these results suggest that the biomarkers of MDD presence are distinct from those associated with change in depression symptoms over time.

\section{Keywords}

Adolescent major depression, resting-state, amygdala, dorsolateral prefrontal cortex, ventromedial prefrontal cortex. 


\section{Introduction}

Major depressive disorder (MDD) is one of the world's major causes of disability (Ferrari et al., 2013). The incidence of major depressive disorder (MDD) increases markedly during adolescence, with estimates of up to $20 \%$ of youths affected (Kessler et al., 2007). Moreover, adolescent-onset depression is often recurrent, persists into adulthood, and is associated with higher risk of negative outcomes (Birmaher et al., 1996). Thus there is a pressing need to develop brain-based biomarkers that are diagnostic of disorder state and that are associated with change in depression severity over time (Dunlop and Mayberg, 2014). These may ultimately aid in making a diagnosis and have clinical value in determining the utility of continuing a treatment intervention early in its course, obviating the need to wait until treatment completion to determine efficacy (Dunlop and Mayberg, 2014).

Increased amygdala activation to emotional stimuli has been linked to adult (Drevets, 2000) and adolescent depression (Hulvershorn et al., 2011; Yang et al., 2010). Normalization of amygdala activation to emotional stimuli has also been associated with successful pharmacological and psychotherapeutic interventions for depression in both adults (Arnone et al., 2012; Fu et al., 2008; Godlewska et al., 2012; Sheline et al., 2001) and adolescents (Straub et al., 2015; Tao et al., 2012). In resting-state functional connectivity (RSFC) studies, reduced amygdala connectivity with the ventral frontal cortex has been observed in depressed adults (Tang et al., 2013; Veer et al., 2010), greater positive amygdala RSFC with the DLPFC has been 
observed in depressed adolescents relative to healthy controls (Pannekoek et al., 2014), and reduced amygdala RSFC with hippocampus and parahippocampus has been associated with greater depression symptom severity in depressed adolescents (Cullen et al., 2014). Finally, recent research in depressed adults has shown that greater symptom improvement in response to treatment was associated with reduced amygdala connectivity with several brain regions (e.g., dorsal midcingulate) critical to emotion processing (Lui et al., 2011; Salomons et al., 2014). These results suggest that the amygdala RSFC may serve as a useful biomarker of treatment response in depressed adolescents.

The amygdala is but one component of a large network of regions that subserve emotion generation and regulation functions. One of these regions, the dorsolateral prefrontal cortex (DLPFC) is critical to executive function (Miller and Cohen, 2001) and is involved in voluntary emotion control (Ochsner and Gross, 2005; Phillips et al., 2008) with recent studies suggesting that it is critical to emotion reappraisal in healthy adults, adolescents, and children (Goldin et al., 2008; McRae et al., 2012). In depressed adults, reduced DLPFC-amygdala connectivity has been reported during emotional regulation (Erk et al., 2010) whereas in healthy controls greater connectivity was associated with more successful regulation (Banks et al., 2007). Furthermore, increased RSFC of a network of regions that includes the DLPFC has been reported in depressed adolescents (Jiao et al., 2011; Jin et al., 2011). The DLPFC is, however, sparsely connected with the amygdala (Price, 2005). Instead it is thought that the DLPFC influences the amygdala indirectly via the ventromedial 
prefrontal cortex (VMPFC) with which it is heavily interconnected (Öngür and Price, 2000).

The VMPFC plays a central role in human social and affective functioning (Mitchell, 2011) with much of its functions accomplished automatically as for example during extinction of previously conditioned behaviors (Milad and Quirk, 2002; Morgan et al., 2003) (see Phillips et al., 2008 for review). Like the DLPFC, the VMPFC is important to emotion reappraisal and is thought to accomplish its role in emotional regulation via its extensive connectivity with subcortical structures such as the amygdala (Ghashghaei et al., 2007). Greater VMPFC activity in combination with reduced amygdala activity has been associated with reduced negative affect in healthy adolescents (Pitskel et al., 2011) and adults (Johnstone et al., 2007; Urry et al., 2006). Increased VMPFC activity when observing happy faces coupled with decreased VMPFC activity when looking at sad faces was observed in depressed adults, whereas the pattern was reversed in healthy adults (Keedwell et al., 2005). Similarly, depressed adolescents displayed reduced amygdala-VMPFC functional connectivity during emotional reappraisal of negative images (Perlman et al., 2012).

The primary aim of the present study was to examine the RSFC of the amygdala in adolescent depression to replicate prior studies in a larger sample with a view to identifying biomarkers of the presence/absence of depression and those potentially associated with change in depression symptoms over time. We hypothesized that, relative to healthy controls, depressed adolescents would display reduced 
connectivity of the amygdala with regions critical to the volitional (DLPFC) and automatic (VMPFC) regulation of emotions. Finally, we explored whether amygdala RSFC would predict changes in depression severity three months later. 


\section{Material and Methods}

\section{Participants}

Of 143 participants recruited, 101 (48 unmedicated MDD and 53 healthy controls (HCL)) were included in this study (see supplement for exclusion/inclusion criteria). Though a subset of these participants was reported on elsewhere (Connolly et al., 2013; Ho et al., 2015; Sacchet et al., 2016), the present investigation includes previously unpublished longitudinal data. See supplement for specific details on overlap with prior studies. Participants provided written informed assent and their parents/legal guardians supplied written informed consent. The institutional review boards at University of California (UC) San Diego, UC San Francisco, Rady Children's Hospital, and the county of San Diego approved this study.

\section{Assessment}

At baseline, all potentially depressed adolescents were administered the Schedule for Affective Disorders and Schizophrenia for School-Age Children-Present and Lifetime Version (Kaufman et al., 1997). At baseline, healthy control participants were administered the Diagnostic Interview Schedule for Children (Shaffer et al., 2000) and Diagnostic Predictive Scale (Lucas et al., 2001) instruments to screen for the presence of DSM-IV-TR Axis I disorders. 
All participants completed the Children's Depression Rating Scale-Revised (CDRS-R) (Poznanski, 1996), the Reynolds Adolescent Depression Scale (RADS-2) (Osman et al., 2010), the Children's Global Assessment Scale (CGAS) (Dyrborg et al., 2000), the Multidimensional Anxiety Scale for Children (MASC) (March et al., 1997), and the Wechsler Abbreviated Scale of Intelligence (Wechsler, 1999) at baseline. At three months follow-up, participants completed the CDRS-R, RADS-2, MASC, and CGAS.

The two groups were well-matched on age, gender, socioeconomic status, and pubertal status. All participants were right-handed. See supplement for details.

\section{Demographics and Clinical Scales Analysis}

Analyses were conducted in R (R Development Core Team, 2012). Baseline between-group differences were assessed using Welch $t$-tests for age, WASI, CDRSR, RADS-2, CGAS, and MASC. Socioeconomic and Tanner stage differences were assessed using the Wilcoxon rank-sum test. Between-group differences in proportions were assessed with the $\chi^{2}$ test of equal proportions. Difference scores from baseline to follow-up were calculated for CDRS-R, RADS-2, CGAS, and MASC (see supplement). Linear mixed effects models evaluated between-group differences in these scores. All tests were two-tailed.

\section{Baseline MR Data Acquisition and Analysis}

Functional magnetic resonance imaging (fMRI) data were acquired on a 3T GE MR750 MRI system (Milwaukee, WI) at UC San Diego. One 8 min 32 sec T2*- 
weighted echo planar image (EPI) scan (256 volumes TR/TE=2s/30ms, flip angle $=90^{\circ}, 64 \times 64$ matrix, $3 \times 3 \times 3 \mathrm{~mm}$ voxels, 40 axial slices, parallel imaging method: ASSET, acceleration factor: 2) was acquired. A T1-weighted (T1w) scan (TR/TE $=8.1 \mathrm{~ms} / 3.17 \mathrm{~ms}$, flip angle $=12^{\circ}, 256 \times 256$ matrix, $1 \times 1 \times 1 \mathrm{~mm}$ voxels, 168 sagittal slices) was acquired to permit spatial normalization and functional localization. Participants were instructed to lay as still as possible, look at a fixation cross centrally displayed on a screen at the foot of the scanner and viewed via a head coil-mounted mirror, and not to fall asleep. After the scan, participants were asked whether they had fallen asleep. None reported having done so.

Analysis was performed using AFNI (Cox, 1996) and FSL (Smith et al., 2004). T1w images were skull-stripped and transformed to MNI152 space using linear (Jenkinson et al., 2002; Jenkinson and Smith, 2001) and nonlinear (Andersson et al., 2007) alignment. Cerebrospinal fluid (CSF), grey matter (GM), and white matter (WM) were then segmented (Zhang et al., 2001).

EPI time-series were slice-time and motion corrected, aligned to the T1w images (Saad et al., 2009), and smoothed with a $4.2 \mathrm{~mm}$ full-width at half-maximum isotropic Gaussian kernel within a GM mask. All data were simultaneously bandpass filtered $(0.009-0.08 \mathrm{~Hz})$ before regression (Hallquist et al., 2013). To control for physiological processes, signal associated with CSF, WM, motion, and their detrended derivatives was removed from the EPI time-series using multiple linear regression (Fox et al., 2005). Censoring of outlier volumes and those contaminated 
by excessive motion was performed (Power et al., 2012). The cleaned time-series were transformed to MNI152 standard space at $3 \times 3 \times 3 \mathrm{~mm}$ resolution for subsequent analyses. See supplement for details.

\section{Amygdala RSFC Analysis}

Two amygdalae seeds (one per hemisphere) were created as the union of the basolateral, superficial and centromedial amygdala regions in the boundaries of the Jülich histological atlas (Amunts et al., 2005). Only voxels with at least $50 \%$ probability of belonging to each of the three subdivisions were included. See supplement for details. The Pearson correlation of the average seed time-series and cleaned whole-brain EPI time-series was computed and subjected to Fisher's r-to-z transform.

\section{Baseline Between-Group RSFC Analysis}

Between-group differences in RSFC of each seed were assessed by whole-brain voxel-wise $t$-tests with subsequent correction for multiple comparisons (see below and supplement). Due to the presence of a between-group difference in full IQ scores (see below), WASI full score was included as a covariate.

\section{Follow-up CDRS-R Regression Analysis}

To explore the relationship between baseline amygdala RSFC and difference in depression symptom ratings between baseline and follow-up, we used voxel-wise whole-brain robust regression implemented in R (R Development Core Team, 2012) within the MDD group. Only CDRS-R change score showed a significant baseline to 
follow-up difference, consequently, we only examined CDRS-R. To obtain unbiased estimates, $t$-statistics were computed using a bootstrap (Davison and Hinkley, 1997) estimate of each partial regression coefficient's standard error. This was accomplished with the boot package (Canty and Ripley, 2015) in R and employed 1000 samples with replacement per voxel. Due to the observation that functional connectivity patterns of the brain can change over time (Fair et al., 2009; Power et al., 2010), age was included as a nuisance covariate and correction for multiple comparisons was subsequently performed (see below and supplement).

\section{Thresholding and Multiple Comparisons Correction}

Between-group and regression analyses were required to pass two-tailed voxel-

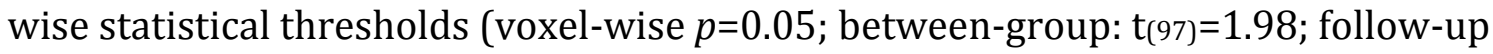
regression: $\left.\mathrm{t}_{(21)}=2.08\right)$. Minimum cluster sizes, determined by Monte-Carlo simulations that accounted for the estimated smoothing, were $4,895 \mu \mathrm{L}$ and 4 , $995 \mu \mathrm{L}$ for the between-group and regression analyses, respectively. Bonferroni correction compensated for the number of amygdala seed regions. The corrected cluster-wise $p$ was $0.05 / 2=0.025$. (See supplement for more details). 


\section{Results}

\section{Demographics and Clinical Scales}

The two groups did not differ on age, socioeconomic status, gender, or Tanner stage (all $p>0.05$ ). The MDDs had lower IQ scores than HCLs (all $p<0.01$ ); thus, full IQ score was included as a covariate in the between-group analysis. The MDD group endorsed greater levels of depression and anxiety and lower levels of psychosocial function than the HCL group (all $p<0.05$ ) at baseline.

Only the CDRS-R change score showed a significant between-group difference $(p<0.05)$ with MDDs displaying reduced CDRS-R score at follow-up compared to controls (see Table 1 and supplement). RADS-2, CGAS, and MASC showed no effect of group (all $p>0.1$; see supplement). Consequently, the follow-up regression analysis only examined CDRS-R.

\section{Baseline Between-Group RSFC Analysis}

Compared to HCL, depressed adolescents showed primarily reduced RSFC between each of the amygdala seeds and the rest of the brain (Table 2). The MDD group displayed reduced connectivity between the right amygdala and the bilateral DLPFC. Connectivity between ventrolateral and ventromedial prefrontal cortex (VLPFC, VMPFC) and right amygdala was also reduced in the MDD group relative to controls. The MDD group exhibited reduced RSFC between the left amygdala and both the left DLPFC and VMPFC. See Figure 1. 


\section{Follow-up CDRS-R Regression Analysis}

Regions showing a significant relationship between change in CDRS-R and amygdala RSFC are shown in Table 3. Greater baseline positive RSFC between the right amygdala and the orbital middle frontal gyrus was associated with greater CDRS-R score at follow-up. Greater baseline positive connectivity between the right amygdala and the bilateral insulae was associated with reduced follow-up CDRS-R score. 


\section{Discussion}

We compared the RSFC of the amygdala in a relatively large group of unmedicated depressed adolescents to a group of well-matched healthy controls and assessed whether RSFC of the amygdala at baseline predicted change in depression severity three months later within the depressed adolescents only. We report three main findings. First, in the baseline analysis, depressed adolescents demonstrated reduced RSFC between bilateral amygdala and DLPFC compared to HCLs. Secondly, also in the baseline analysis, depressed adolescents showed decreased RSFC between amygdala and VLPFC and VMPFC compared to HCLs. Finally, in the followup analysis, more positive RSFC between the amygdala and bilateral insulae at baseline is associated with greater reduction in depression symptom severity over time. These results support the hypothesis that adolescent depression may be characterized by disruption of circuits critical to volitional and automatic regulation of emotion. Furthermore, change in depression symptoms over time may be related to aberrant circuits involved in the integration of emotional and hedonic information. Interestingly, our results suggest that biomarkers of MDD in adolescents are distinct from those associated with change in depression symptoms over time.

We observed significantly reduced RSFC between DLPFC and the amygdalae in MDD compared to HCL. The DLPFC is a core region involved in executive brain function (Miller and Cohen, 2001), is involved in the volitional regulation of emotions 
(Ochsner and Gross, 2005; Phillips et al., 2008) and is important to the reappraisal of emotional stimuli in healthy children, adolescents and adults (Goldin et al., 2008; McRae et al., 2012). Greater amygdala-DLPFC connectivity has been shown to be associated with more successful regulation of emotions (Banks et al., 2007) and reduced DLPFC activation has been observed in depressed adults during emotional regulation (Erk et al., 2010) which moderates with remission (Mayberg et al., 1999). Resting-state fMRI studies reported reduced intra-regional synchronization of the BOLD signal in of the DLPFC in both depressed elderly adults (Liu et al., 2012) and older adults with sub-threshold depression (Ma et al., 2013). Of the RSFC studies of depressed adolescents reporting DLPFC involvement, one has identified elevated DLPFC activity at rest (Jiao et al., 2011) while another described increased connectivity of the DLPFC in depressed adolescents (Jin et al., 2011). However, neither of these studies used seed-based RSFC analyses, so the discrepancy with the present results could be methodological in origin. The involvement of the DLPFC in reappraisal of emotional stimuli and regulation of emotion coupled with the observation of reduced amygdala-DLPFC connectivity suggest disruption in the network of brain regions responsible for emotion regulation in adolescent depression.

We observed significantly reduced RSFC between the VLPFC and VMPFC and the amygdalae in MDD compared to controls. The VMPFC is an important structure in human social and affective function (Damasio, 1996; Fellows, 2011; Quirk and Beer, 2006) and is centrally implicated in the pathophysiology of mood disorders (Myers- 
Schulz and Koenigs, 2012; Price, 1999). VMPFC is critical to affect processing and regulation, particularly by changing conditioned associations of stimuli, facilitating the regulation of responses to conditioned and unconditioned stimuli, and by mediating the complex relationship between internal states and external stimuli (Mitchell, 2011). The amygdala is similarly critical to the pathophysiology of depression (Drevets, 2000; Perlman et al., 2012) and the two structures are richly interconnected (Öngür, 2000). The VMPFC also plays a role in emotional reappraisal. For example, greater VMPFC activation coupled with reduced amygdala activity has been associated with reduced negative affect (Johnstone et al., 2007; Urry et al., 2006) during reappraisal in healthy adults. Ventrolateral PFC (VLPFC) activity has also been associated with amygdala regulation in healthy adults with the suggestion that, in the absence of direct VLPFC-amygdala structural connectivity (Price, 2005), the effect is mediated by the VMPFC (Johnstone et al., 2007). In the child and adolescent literature, VMPFC activity has been associated with reappraisal with activity declining with age (McRae et al., 2012). The inverse relationship between VMPFC and amygdala activity reported in adults (Johnstone et al., 2007; Urry et al., 2006) has also been observed in adolescents during emotional regulation (Pitskel et al., 2011). Resting-state studies of depressed adults have shown reduced connectivity between amygdala and ventral PFC in treatment naïve adults (Ramasubbu et al., 2014; Tang et al., 2013). Additionally, increased connectivity in a network including the ventromedial and orbital frontal regions has been reported though with no amygdala involvement (Zhu et al., 2012). Only one study in a sample of depressed adolescents has reported differences involving amygdala and ventral 
PFC. Using a graph-theoretic approach, increased connectivity among a network of regions involving the amygdala and ventromedial PFC has been reported (Jin et al., 2011). Reconciling the discrepant nature of these findings in adults and adolescents is complicated by the use of different analytic techniques. In light of the importance of PFC, including both ventrolateral and ventromedial portions, to emotion regulation, the altered connectivity between these regions and the amygdala further suggests the disruption of circuits critical to emotional regulation in adolescent depression.

In the MDD group, we observed greater positive connectivity between the right amygdala and right insula and between the left amygdala and the left insula (Figure 2) that was associated with greater reduction in depression severity over time. The insula is thought to be critical to the integration and awareness of autonomic, visceral, and hedonic information (Craig, 2009) and it has been implicated in depression-relevant processes such as interoception, emotional self-awareness, decision making and cognitive control (Craig, 2009). A growing body of literature has identified insular dysfunction in adolescents at-risk for (Gotlib et al., 2010) and with depression (Ho et al., 2015; 2013; 2014; Perlman et al., 2012; Yang et al., 2010). Additionally, resting-state studies showed altered patterns of insular connectivity in both adults (Jacobs et al., 2016; Tahmasian et al., 2013; Veer et al., 2010) and adolescents (Connolly et al., 2013; Cullen et al., 2009; Jin et al., 2011). Change in insula activity arises in diverse treatments such as deep brain stimulation (Mayberg et al., 2005), mindfulness (Fu et al., 2013), and medication (Kennedy et al., 
2001). It has been suggested that insular activity may be a useful treatment-specific biomarker to identify patients who may most benefit from either cognitive behavioral therapy (CBT) or pharmacotherapy (McGrath et al., 2013). The present results, in combination with these prior studies, suggest that in addition to insular activation, amygdala-insula RSFC may be related to change in symptom severity over time.

Three prior studies have examined amygdalar RSFC in children (Luking et al., 2011) and adolescents (Cullen et al., 2014; Pannekoek et al., 2014). The regions identified by Luking et al. (Luking et al., 2011) and Pannekoek et al. (Pannekoek et al., 2014) overlap with those reported here insofar as both studies report altered amygdalar functional connectivity with regions important to emotion regulation (e.g., middle and inferior frontal gyri). Differences among these and the current results arise in the direction of the RSFC relationship: Luking et al. report reduced negative connectivity between amygdala and a network that included DLPFC, Pannekoek et al. reported greater positive connectivity between the amygdala and DLPFC, whereas here we reported reduced positive connectivity between amygdala and DLPFC. The results reported by Cullen et al (Cullen et al., 2014) stand in contrast the present results and those of Pannekoek and Luking insofar as Cullen reported no amygdalar connectivity differences with any dorsolateral executive regions. The results reported herein differ from adults studies that showed that amygdala RSFC was related to treatment response (Lui et al., 2011; Salomons et al., 2014). These adult studies showed that reduced connectivity within a network of structures, 
including limbic, prefrontal and insular regions that are known to be important to emotion processing (Kober et al., 2008) was associated with better treatment response. The reasons for the discrepancies among these studies are various and likely include diagnostic heterogeneity, age range, illness chronicity, developmental stage, inclusion/exclusion criteria, analytic techniques, and sample size, among others. Developmental stage may explain a substantial amount of the heterogeneity in amygdala RSFC as changes in amygdala connectivity directionality have been associated with maturation (Gee et al., 2013). The lack of consistency both within the adolescent studies and between adolescent and adult studies will require larger studies, possibly involving the pooling of data from multiple sites as is now becoming possible with the advent of consortia such as ENIGMA (Thompson et al., 2015; 2014) and IMAGEN (Schumann et al., 2010). Consortia such as these can facilitate the exploration of indictors of depression and predictors of treatment response across the course of development, thus enabling the exploration of the consistency of these biomarkers over ontogenesis.

Our results are clinically significant insofar as they show that the biomarkers of MDD presence are distinct from those associated with change in depression symptoms over time. This is consistent with the notion that biomarkers of illness presence need not overlap with those associated with change in the illness symptoms or predictors of future illness state or treatment response/success (Dunlop and Mayberg, 2014). Although our results were not derived from the assessment of specific treatments (which the present study was underpowered to 
assess), they may form a basis for the development of biomarkers that may adjudicate treatment efficacy and/or lead to the development of treatment-selection biomarkers that permit the personalization of treatment and maximization of treatment outcomes.

While this is the largest RSFC investigation of amygdala connectivity in adolescent depression, this study is not without limitations. While there is considerable theoretical and empirical evidence in the neuroimaging literature of MDD to focus our analyses on the amygdala, by concentrating on the amygdala, RSFC alterations in other networks may have been overlooked. Moreover, several of our participants had comorbid anxiety disorders; as adolescent depression is a highly comorbid disorder (Choy et al., 2007; Costello et al., 2003; Kilpatrick et al., 2003), the inclusion of such participants makes our sample more representative of patients seen in clinics and contributes to the generalizability of our findings. Nevertheless, studies investigating amygdala RSFC in anxiety disorders (Hamm et al., 2014; Roy et al., 2013) have reported results that overlap with some of those reported herein. Future studies are therefore required to ascertain the specificity of the present results. We did not observe widespread reduction in connectivity in the MDD group as compared to the healthy controls in the present sample of participants when investigating a small number of seeds (amygdala and (in the supplement) subgenual anterior cingulate and DLPFC). Nevertheless, we cannot rule out the possibility that MDD may be characterized by widespread reduction in connectivity that may only be observable when examining the interrelationships among a large network of 
regions (Sacchet et al., 2016). Finally, future studies are required to replicate our findings predicting change in depression symptom severity from amygdala RSFC. The depressed adolescents in the present study were not part of an intervention designed to deliver standardized treatment. Rather, they were treated by their own psychiatrists and underwent a variety of treatments including no therapy, psychotherapy, and medication. This makes inferring the source of the effect in the follow-up analysis difficult. In particular, future studies should endeavor to establish whether amygdala-insula RSFC is a biomarker of response to a particular treatment (e.g., CBT, pharmacotherapy) and thus may serve as a treatment-specific biomarker or whether it is a more general index of treatment response irrespective of treatment type. Furthermore, these should include larger samples and ideally include multiple timepoints so as to more fully characterize the temporal relationship between RSFC and depression symptomatology.

In summary, we examined the RSFC of the amygdalae in a large sample of medication-naive depressed adolescents compared to well-matched healthy controls. Relative to controls, depressed adolescents exhibited reduced amydalar connectivity with the DLPFC, VMPFC, and VLPFC. Within the depressed adolescents, greater positive RSFC between amygdala and insulae was associated with greater reduction in depression severity over time. These results suggest that adolescent depression may be characterized by dysfunction of the neural circuits underpinning emotional regulation, whereas those subserving affective integration (amygdala- 
insula) may index changes in depression symptom severity and may therefore potentially serve as a candidate biomarker for treatment response. 


\section{Acknowledgements}

Drs. Connolly and Yang had full access to all the data in the study and take responsibility for the integrity of the data and the accuracy of the data analysis.

We want to thank the teenagers who have participated in the study. We also wish to thank Kevin Han, Jing (James) Wu, Mary Luna, and Audrey Fortezzo for their help.

This work was supported by the Swedish Research Council (E.H.B., grant number 350-2012-303); the Swedish Society of Medicine (E.H.B., grant number SLS244671) and the Sweden American Association to EHB; the Brain and Behavior Research Foundation (formerly NARSAD) to T.T.Y.; the National Institute of Mental Health (T.T.Y., R01MH085734; K.Z.L., K01MH097978; O.T., R21AT009173); by the National Science Foundation (NSF) Integrative Graduate Education and Research Traineeship (IGERT) Recipient Award 0801700 to M.D.S; NSF Graduate Research Fellowship Program (GRFP) DGE-1147470 to M.D.S.; by the American Foundation for Suicide Prevention (PDF-1-064-13) to T.C.H.; and salary support for A.N.S. by the Center of Excellence in Stress and Mental Health and by a Veteran's Affairs Merit Award (I01CX000715).

The funding agencies played no role in the design and conduct of the study; collection, management, analysis, and interpretation of the data; and preparation, review, or approval of the manuscript. The views expressed in this article are those of the authors and do not reflect the official policy or position of the United States or Swedish governments. 


\section{Figure Captions}

Figure 1. Regions that showed a significant baseline between-group differences in the functional connectivity of the amygdalae. Bar charts depict mean functional connectivity with the amygdala seed. Error-bars indicate standard error of the mean. PFC, prefrontal cortex.

Figure 2. Regions that showed a significant relationship between amygdala functional connectivity and change in depression symptoms over three months. $\Delta$ CDRS- $\mathrm{R}<0$ implies a reduction of CDRS-R score over time.

Table 1. Participant demographic and clinical characteristics.

Table 2. Brain regions showing between group differences in the resting-state functional connectivity of the amygdala seeds.

Table 3. Brain regions showing a relationship between baseline resting-state functional connectivity of the amygdala and change in CDRS-R score from baseline to three months follow-up. 


\section{References}

Amunts, K., Kedo, O., Kindler, M., Pieperhoff, P., Mohlberg, H., Shah, N.J., Habel, U., Schneider, F., Zilles, K., 2005. Cytoarchitectonic mapping of the human amygdala, hippocampal region and entorhinal cortex: intersubject variability and probability maps. Anat Embryol 210, 343-352. doi:10.1007/s00429-0050025-5

Andersson, J.L.R., Jenkinson, M., Smith, S.M., 2007. Non-linear registration, aka Spatial normalisation (No. TR07JA2). FMRIB, University of Oxford, Oxford, UK.

Arnone, D., McKie, S., Elliott, R., Thomas, E.J., Downey, D., Juhasz, G., Williams, S.R., Deakin, J.F.W., Anderson, I.M., 2012. Increased amygdala responses to sad but not fearful faces in major depression: relation to mood state and pharmacological treatment. Am J Psychiatry 169, 841-850. doi:10.1176/appi.ajp.2012.11121774

Banks, S.J., Eddy, K.T., Angstadt, M., Nathan, P.J., Phan, K.L., 2007. Amygdala-frontal connectivity during emotion regulation. Soc Cogn Affect Neurosci 2, 303-312. doi:10.1093/scan/nsm029

Birmaher, B., Ryan, N.D., Williamson, D.E., Brent, D.A., Kaufman, J., Dahl, R.E., Perel, J., Nelson, B., 1996. Childhood and adolescent depression: a review of the past 10 years. Part I. J Am Acad Child Adolesc Psychiatry 35, 1427-1439. doi:10.1097/00004583-199611000-00011

Canty, A., Ripley, B., 2015. Boot: Bootstrap R (S-Plus) Functions.

Choy, Y., Fyer, A.J., Goodwin, R.D., 2007. Specific phobia and comorbid depression: a closer look at the National Comorbidity Survey data. Compr Psychiatry 48, 132136. doi:10.1016/j.comppsych.2006.10.010

Connolly, C.G., Wu, J., Ho, T.C., Hoeft, F., Wolkowitz, O., Eisendrath, S., Frank, G., Hendren, R., Max, J.E., Paulus, M.P., Tapert, S.F., Banerjee, D., Simmons, A.N., Yang, T.T., 2013. Resting-state functional connectivity of subgenual anterior cingulate cortex in depressed adolescents. Biol Psychiatry 74, 898-907. doi:10.1016/j.biopsych.2013.05.036

Costello, E.J., Mustillo, S., Erkanli, A., Keeler, G., Angold, A., 2003. Prevalence and development of psychiatric disorders in childhood and adolescence. Arch Gen Psychiatry 60, 837-844. doi:10.1001/archpsyc.60.8.837

Cox, R.W., 1996. AFNI: software for analysis and visualization of functional magnetic resonance neuroimages. Comput. Biomed. Res. 29, 162-173.

Craig, A.D.B., 2009. How do you feel-now? The anterior insula and human awareness. Nat Rev Neurosci 10, 59-70. doi:10.1038/nrn2555

Cullen, K.R., Gee, D.G., Klimes-Dougan, B., Gabbay, V., Hulvershorn, L.A., Mueller, B.A., Camchong, J., Bell, C.J., Houri, A., Kumra, S., Lim, K.O., Castellanos, F.X., Milham, M.P., 2009. A preliminary study of functional connectivity in comorbid adolescent depression. Neuroscience Lett 460, 227-231. doi:10.1016/j.neulet.2009.05.022

Cullen, K.R., Westlund, M.K., Klimes-Dougan, B., Mueller, B.A., Houri, A., Eberly, L.E., Lim, K.O., 2014. Abnormal amygdala resting-state functional connectivity in 
adolescent depression. JAMA Psychiatry 71, 1138-1147.

doi:10.1001/jamapsychiatry.2014.1087

Damasio, A.R., 1996. The somatic marker hypothesis and the possible functions of the prefrontal cortex. Philos Trans R Soc Lond B Biol Sci 351, 1413-1420. doi:10.1098/rstb.1996.0125

Davison, A.C., Hinkley, D.V., 1997. Bootstrap methods and their application. Cambridge University Press, Cambridge. doi:10.1017/CB09780511802843

Drevets, W.C., 2000. Neuroimaging studies of mood disorders. Biol Psychiatry 48, 813-829.

Dunlop, B.W., Mayberg, H.S., 2014. Neuroimaging-based biomarkers for treatment selection in major depressive disorder. Dialogues Clin Neurosci 16, 479-490.

Dyrborg, J., Larsen, F.W., Nielsen, S., Byman, J., Nielsen, B.B., Gautre-Delay, F., 2000. The Children's Global Assessment Scale (CGAS) and Global Assessment of Psychosocial Disability (GAPD) in clinical practice--substance and reliability as judged by intraclass correlations. Eur Child Adolesc Psychiatry 9, 195-201.

Erk, S., Mikschl, A., Stier, S., Ciaramidaro, A., Gapp, V., Weber, B., Walter, H., 2010. Acute and sustained effects of cognitive emotion regulation in major depression. J Neurosci 30, 15726-15734. doi:10.1523/JNEUROSCI.1856-10.2010

Fair, D.A., Cohen, A.L., Power, J.D., Dosenbach, N.U.F., Church, J.A., Miezin, F.M., Schlaggar, B.L., Petersen, S.E., 2009. Functional brain networks develop from a "local to distributed" organization. PLoS Comp Biol 5, e1000381. doi:10.1371/journal.pcbi.1000381

Fellows, L.K., 2011. Orbitofrontal contributions to value-based decision making: evidence from humans with frontal lobe damage. Ann N Y Acad Sci 1239, 51-58. doi:10.1111/j.1749-6632.2011.06229.x

Ferrari, A.J., Charlson, F.J., Norman, R.E., Patten, S.B., Freedman, G., Murray, C.J.L., Vos, T., Whiteford, H.A., 2013. Burden of depressive disorders by country, sex, age, and year: findings from the global burden of disease study 2010. Plos Med 10, e1001547. doi:10.1371/journal.pmed.1001547

Fox, M.D., Snyder, A.Z., Vincent, J.L., Corbetta, M., Van Essen, D.C., Raichle, M.E., 2005. The human brain is intrinsically organized into dynamic, anticorrelated functional networks. Proc Natl Acad Sci USA 102, 9673-9678. doi:10.1073/pnas.0504136102

Fu, C.H.Y., Steiner, H., Costafreda, S.G., 2013. Predictive neural biomarkers of clinical response in depression: a meta-analysis of functional and structural neuroimaging studies of pharmacological and psychological therapies. Neurobiol. Dis. 52, 75-83. doi:10.1016/j.nbd.2012.05.008

Fu, C.H.Y., Williams, S.C.R., Cleare, A.J., Scott, J., Mitterschiffthaler, M.T., Walsh, N.D., Donaldson, C., Suckling, J., Andrew, C., Steiner, H., Murray, R.M., 2008. Neural responses to sad facial expressions in major depression following cognitive behavioral therapy. Biol Psychiatry 64, 505-512.

doi:10.1016/j.biopsych.2008.04.033

Gee, D.G., Humphreys, K.L., Flannery, J., Goff, B., Telzer, E.H., Shapiro, M., Hare, T.A., Bookheimer, S.Y., Tottenham, N., 2013. A Developmental Shift from Positive to Negative Connectivity in Human Amygdala-Prefrontal Circuitry. J Neurosci 33, 4584-4593. doi:10.1523/JNEUROSCI.3446-12.2013 
Ghashghaei, H.T., Hilgetag, C.C., Barbas, H., 2007. Sequence of information processing for emotions based on the anatomic dialogue between prefrontal cortex and amygdala. NeuroImage 34, 905-923. doi:10.1016/j.neuroimage.2006.09.046

Godlewska, B.R., Norbury, R., Selvaraj, S., Cowen, P.J., Harmer, C.J., 2012. Short-term SSRI treatment normalises amygdala hyperactivity in depressed patients. Psychol Med 42, 2609-2617. doi:10.1017/S0033291712000591

Goldin, P.R., McRae, K., Ramel, W., Gross, J.J., 2008. The neural bases of emotion regulation: reappraisal and suppression of negative emotion. Biol Psychiatry 63, 577-586. doi:10.1016/j.biopsych.2007.05.031

Gotlib, I.H., Hamilton, J.P., Cooney, R.E., Singh, M.K., Henry, M.L., Joormann, J., 2010. Neural Processing of Reward and Loss in Girls at Risk for Major Depression. Arch Gen Psychiatry 67, 380-387. doi:10.1001/archgenpsychiatry.2010.13

Hallquist, M.N., Hwang, K., Luna, B., 2013. The nuisance of nuisance regression: spectral misspecification in a common approach to resting-state fMRI preprocessing reintroduces noise and obscures functional connectivity. NeuroImage 82, 208-225. doi:10.1016/j.neuroimage.2013.05.116

Hamm, L.L., Jacobs, R.H., Johnson, M.W., Fitzgerald, D.A., Fitzgerald, K.D., Langenecker, S.A., Monk, C.S., Phan, K.L., 2014. Aberrant amygdala functional connectivity at rest in pediatric anxiety disorders. Biol Mood Anxiety Disord 4, 15-15. doi:10.1186/s13587-014-0015-4

Ho, T.C., Connolly, C.G., Henje Blom, E., LeWinn, K.Z., Strigo, I.A., Paulus, M.P., Frank, G., Max, J.E., Wu, J., Chan, M., Tapert, S.F., Simmons, A.N., Yang, T.T., 2015. Emotion-Dependent Functional Connectivity of the Default Mode Network in Adolescent Depression. Biol Psychiatry 78, 635-646.

doi:10.1016/j.biopsych.2014.09.002

Ho, T.C., Wu, J., Shin, D.D., Liu, T.T., Tapert, S.F., Yang, G., Connolly, C.G., Frank, G.K.W., Max, J.E., Wolkowitz, O., Eisendrath, S., Hoeft, F., Banerjee, D., Hood, K., Hendren, R.L., Paulus, M.P., Simmons, A.N., Yang, T.T., 2013. Altered cerebral perfusion in executive, affective, and motor networks during adolescent depression. J Am Acad Child Adolesc Psychiatry 52, 1076-1091.e2. doi:10.1016/j.jaac.2013.07.008

Ho, T.C., Yang, G., Wu, J., Cassey, P., Brown, S.D., Hoang, N., Chan, M., Connolly, C.G., Henje Blom, E., Duncan, L.G., Chesney, M.A., Paulus, M.P., Max, J.E., Patel, R., Simmons, A.N., Yang, T.T., 2014. Functional connectivity of negative emotional processing in adolescent depression. J Affect Disord 155, 65-74. doi:10.1016/j.jad.2013.10.025

Hulvershorn, L.A., Cullen, K.R., Anand, A., 2011. Toward dysfunctional connectivity: a review of neuroimaging findings in pediatric major depressive disorder. Brain Imaging Behav 5, 307-328. doi:10.1007/s11682-011-9134-3

Jacobs, R.H., Barba, A., Gowins, J.R., Klumpp, H., Jenkins, L.M., Mickey, B.J., Ajilore, O., Peciña, M., Sikora, M., Ryan, K.A., Hsu, D.T., Welsh, R.C., Zubieta, J.K., Phan, K.L., Langenecker, S.A., 2016. Decoupling of the amygdala to other salience network regions in adolescent-onset recurrent major depressive disorder. Psychol Med 46, 1-13. doi:10.1017/S0033291715002615

Jenkinson, M., Bannister, P., Brady, M., Smith, S.M., 2002. Improved optimization for 
the robust and accurate linear registration and motion correction of brain images. NeuroImage 17, 825-841.

Jenkinson, M., Smith, S.M., 2001. A global optimisation method for robust affine registration of brain images. Med Image Anal 5, 143-156. doi:10.1016/S13618415(01)00036-6

Jiao, Q., Ding, J., Lu, G., Su, L., Zhang, Z., Wang, Z., Zhong, Y., Li, K., Ding, M., Liu, Y., 2011. Increased activity imbalance in fronto-subcortical circuits in adolescents with major depression. PLoS ONE 6, e25159-e25159.

doi:10.1371/journal.pone.0025159

Jin, C., Gao, C., Chen, C., Ma, S., Netra, R., Wang, Y., Zhang, M., Li, D., 2011. A preliminary study of the dysregulation of the resting networks in first-episode medication-naive adolescent depression. Neuroscience Lett 503, 105-109. doi:10.1016/j.neulet.2011.08.017

Johnstone, T., van Reekum, C.M., Urry, H.L., Kalin, N.H., Davidson, R.J., 2007. Failure to regulate: counterproductive recruitment of top-down prefrontal-subcortical circuitry in major depression. J Neurosci 27, 8877-8884. doi:10.1523/JNEUROSCI.2063-07.2007

Kaufman, J., Birmaher, B., Brent, D., Rao, U.M.A., Flynn, C., Moreci, P., Williamson, D., Ryan, N., 1997. Schedule for Affective Disorders and Schizophrenia for SchoolAge Children-Present and Lifetime Version (K-SADS-PL): Initial Reliability and Validity Data. J Am Acad Child Adolesc Psychiatry 36, 980-988. doi:10.1097/00004583-199707000-00021

Keedwell, P.A., Andrew, C., Williams, S., Brammer, M.J., Phillips, M.L., 2005. A double dissociation of ventromedial prefrontal cortical responses to sad and happy stimuli in depressed and healthy individuals. Biol Psychiatry 58, 495-503. doi:10.1016/j.biopsych.2005.04.035

Kennedy, S.H., Evans, K.R., Krüger, S., Mayberg, H.S., Meyer, J.H., McCann, S., Arifuzzman, A.I., Houle, S., Vaccarino, F.J., 2001. Changes in regional brain glucose metabolism measured with positron emission tomography after paroxetine treatment of major depression. Am J Psychiatry 158, 899-905.

Kessler, R.C., Angermeyer, M., Anthony, J.C., Graaf, R.D., Demyttenaere, K., Gasquet, I., Girolamo, G.D., Gluzman, S., Gureje, O., Haro, J.M., Kawakami, N., Karam, A., Levinson, D., Mora, M.E.M., Oakley Browne, M.A., Posada-Villa, J., Stein, D.J., Tsang, C.H.A., Aguilar-Gaxiola, S., Alonso, J., Lee, S., Heeringa, S., Pennell, B.-E., Berglund, P., Gruber, M.J., Petukhova, M., Chatterji, S., Üstün, T.B., 2007. Lifetime prevalence and age-of-onset distributions of mental disorders in the World Health Organization's World Mental Health Survey Initiative. World Psychiatry 6, 168-176.

Kilpatrick, D.G., Ruggiero, K.J., Acierno, R., Saunders, B.E., Resnick, H.S., Best, C.L., 2003. Violence and risk of PTSD, major depression, substance abuse/dependence, and comorbidity: Results from the National Survey of Adolescents. J Consult Clin Psych 71, 692-700. doi:10.1037/0022-006X.71.4.692

Kober, H., Barrett, L.F., Joseph, J., Bliss-Moreau, E., Lindquist, K., Wager, T.D., 2008. Functional grouping and cortical-subcortical interactions in emotion: a metaanalysis of neuroimaging studies. Neurolmage 42, 998-1031. doi:10.1016/j.neuroimage.2008.03.059 
Liu, F., Hu, M., Wang, S., Guo, W., Zhao, J., Li, J., Xun, G., Long, Z., Zhang, J., Wang, Y., Zeng, L., Gao, Q., Wooderson, S.C., Chen, J., Chen, H., 2012. Abnormal regional spontaneous neural activity in first-episode, treatment-naive patients with latelife depression: A resting-state fMRI study. Prog Neuro-Psychoph 39, 326-331. doi:10.1016/j.pnpbp.2012.07.004

Lucas, C.P., Zhang, H., Fisher, P.W., Shaffer, D., Regier, D.A., Narrow, W.E., Bourdon, K., Dulcan, M.K., Canino, G., Rubio-Stipec, M., Lahey, B.B., Friman, P., 2001. The DISC Predictive Scales (DPS): efficiently screening for diagnoses. J Am Acad Child Adolesc Psychiatry 40, 443-449. doi:10.1097/00004583-20010400000013

Lui, S., Wu, Q., Qiu, L., Yang, X., Kuang, W., Chan, R.C.K., Huang, X., Kemp, G.J., Mechelli, A., Gong, Q., 2011. Resting-State Functional Connectivity in Treatment-Resistant Depression. American Journal of Psychiatry 168, 642-648.

doi:10.1176/appi.ajp.2010.10101419

Luking, K.R., Repovš, G., Belden, A.C., Gaffrey, M.S., Botteron, K.N., Luby, J.L., Barch, D.M., 2011. Functional connectivity of the amygdala in early-childhood-onset depression. J Am Acad Child Adolesc Psychiatry 50, 1027-10e3. doi:10.1016/j.jaac.2011.07.019

Ma, Z., Li, R., Yu, J., He, Y., Li, J., 2013. Alterations in regional homogeneity of spontaneous brain activity in late-life subthreshold depression. PLoS ONE 8, e53148-e53148. doi:10.1371/journal.pone.0053148

March, J.S., Parker, J.D., Sullivan, K., Stallings, P., Conners, C.K., 1997. The Multidimensional Anxiety Scale for Children (MASC): factor structure, reliability, and validity. J Am Acad Child Adolesc Psychiatry 36, 554-565.

doi:10.1097/00004583-199704000-00019

Mayberg, H.S., Liotti, M., Brannan, S.K., McGinnis, S., Mahurin, R.K., Jerabek, P.A., Silva, J.A., Tekell, J.L., Martin, C.C., Lancaster, J.L., Fox, P.T., 1999. Reciprocal limbic-cortical function and negative mood: converging PET findings in depression and normal sadness. Am J Psychiatry 156, 675-682.

Mayberg, H.S., Lozano, A.M., Voon, V., McNeely, H.E., Seminowicz, D.A., Hamani, C., Schwalb, J.M., Kennedy, S.H., 2005. Deep Brain Stimulation for TreatmentResistant Depression. Neuron 45, 651-660. doi:10.1016/j.neuron.2005.02.014

McGrath, C.L., Kelley, M.E., Holtzheimer, P.E., Dunlop, B.W., Craighead, W.E., Franco, A.R., Craddock, R.C., Mayberg, H.S., 2013. Toward a neuroimaging treatment selection biomarker for major depressive disorder. JAMA Psychiatry 70, 821829. doi:10.1001/jamapsychiatry.2013.143

McRae, K., Gross, J.J., Weber, J., Robertson, E.R., Sokol-Hessner, P., Ray, R.D., Gabrieli, J.D.E., Ochsner, K.N., 2012. The development of emotion regulation: an fMRI study of cognitive reappraisal in children, adolescents and young adults. Soc Cogn Affect Neurosci 7, 11-22. doi:10.1093/scan/nsr093

Milad, M.R., Quirk, G.J., 2002. Neurons in medial prefrontal cortex signal memory for fear extinction. Nature 420, 70-74. doi:10.1038/nature01138

Miller, E.K., Cohen, J.D., 2001. An integrative theory of prefrontal cortex function. Annu Rev Neurosci 24, 167-202. doi:10.1146/annurev.neuro.24.1.167

Mitchell, D.G.V., 2011. The nexus between decision making and emotion regulation: a review of convergent neurocognitive substrates. Behav Brain Res 217, 215- 
231. doi:10.1016/j.bbr.2010.10.030

Morgan, M.A., Schulkin, J., LeDoux, J.E., 2003. Ventral medial prefrontal cortex and emotional perseveration: the memory for prior extinction training. Behav Brain Res 146, 121-130.

Myers-Schulz, B., Koenigs, M., 2012. Functional anatomy of ventromedial prefrontal cortex: implications for mood and anxiety disorders. Mol Psychiatr 17, 132-141. doi:10.1038/mp.2011.88

Ochsner, K.N., Gross, J.J., 2005. The cognitive control of emotion. Trends Cogn Sci 9, 242-249. doi:10.1016/j.tics.2005.03.010

Osman, A., Gutierrez, P.M., Bagge, C.L., Fang, Q., Emmerich, A., 2010. Reynolds adolescent depression scale-second edition: a reliable and useful instrument. J Clin Psychol 66, 1324-1345. doi:10.1002/jclp.20727

Öngür, D., 2000. The Organization of Networks within the Orbital and Medial Prefrontal Cortex of Rats, Monkeys and Humans. Cereb cortex 10, 206-219. doi:10.1093/cercor/10.3.206

Öngür, D., Price, J.L., 2000. The organization of networks within the orbital and medial prefrontal cortex of rats, monkeys and humans. Cereb cortex 10, 206219. doi:10.1093/cercor/10.3.206

Pannekoek, J.N., van der Werff, S.J.A., Meens, P.H.F., van den Bulk, B.G., Jolles, D.D., Veer, I.M., van Lang, N.D.J., Rombouts, S.A.R.B., van der Wee, N.J.A., Vermeiren, R.R.J.M., 2014. Aberrant resting-state functional connectivity in limbic and salience networks in treatment--naïve clinically depressed adolescents. J Child Psychol Psychiatry 55, 1317-1327. doi:10.1111/jcpp.12266

Perlman, G., Simmons, A.N., Wu, J., Hahn, K.S., Tapert, S.F., Max, J.E., Paulus, M.P., Brown, G.G., Frank, G.K., Campbell-Sills, L., Yang, T.T., 2012. Amygdala response and functional connectivity during emotion regulation: A study of 14 depressed adolescents. J Affect Disord 139, 75-84. doi:10.1016/j.jad.2012.01.044

Phillips, M.L., Ladouceur, C.D., Drevets, W.C., 2008. A neural model of voluntary and automatic emotion regulation: implications for understanding the pathophysiology and neurodevelopment of bipolar disorder. Mol Psychiatr 13, 833-857. doi:10.1038/mp.2008.65

Pitskel, N.B., Bolling, D.Z., Kaiser, M.D., Crowley, M.J., Pelphrey, K.A., 2011. How grossed out are you? The neural bases of emotion regulation from childhood to adolescence. Developmental Cognitive Neuroscience 1, 324-337.

doi:10.1016/j.dcn.2011.03.004

Power, J.D., Barnes, K.A., Snyder, A.Z., Schlaggar, B.L., Petersen, S.E., 2012. Spurious but systematic correlations in functional connectivity MRI networks arise from subject motion. NeuroImage 59, 2142-2154.

doi:10.1016/j.neuroimage.2011.10.018

Power, J.D., Fair, D.A., Schlaggar, B.L., Petersen, S.E., 2010. The development of human functional brain networks. Neuron 67, 735-748.

doi:10.1016/j.neuron.2010.08.017

Poznanski, E.O., 1996. Children's Depression Rating Scale-Revised (CDRS-R). Western Psychological Services, Los Angeles.

Price, J.L., 2005. Free will versus survival: Brain systems that underlie intrinsic constraints on behavior. J Comp Neurol 493, 132-139. doi:10.1002/cne.20750 
Price, J.L., 1999. Prefrontal Cortical Networks Related to Visceral Function and Mood. Ann N Y Acad Sci 877, 383-396. doi:10.1111/j.1749-

6632.1999.tb09278.x

Quirk, G.J., Beer, J.S., 2006. Prefrontal involvement in the regulation of emotion: convergence of rat and human studies. Curr Opin Neurobiol 16, 723-727. doi:10.1016/j.conb.2006.07.004

R Development Core Team, 2012. R: A Language and Environment for Statistical Computing. R Foundation for Statistical Computing, Vienna, Austria.

Ramasubbu, R., Konduru, N., Cortese, F., Bray, S., Gaxiola-Valdez, I., Goodyear, B., 2014. Reduced intrinsic connectivity of amygdala in adults with major depressive disorder. Front Psychiatry 5, 17. doi:10.3389/fpsyt.2014.00017

Roy, A.K., Fudge, J.L., Kelly, A.M.C., Perry, J.S.A., Daniele, T., Carlisi, C., Benson, B., Castellanos, F.X., Milham, M.P., Pine, D.S., Ernst, M., 2013. Intrinsic functional connectivity of amygdala-based networks in adolescent generalized anxiety disorder. J Am Acad Child Adolesc Psychiatry 52, 290-299.e2. doi:10.1016/j.jaac.2012.12.010

Saad, Z.S., Glen, D.R., Chen, G., Beauchamp, M.S., Desai, R., Cox, R.W., 2009. A new method for improving functional-to-structural MRI alignment using local Pearson correlation. NeuroImage 44, 839-848. doi:10.1016/j.neuroimage.2008.09.037

Sacchet, M.D., Ho, T.C., Connolly, C.G., Tymofiyeva, O., LeWinn, K.Z., Han, L.K., Blom, E.H., Tapert, S.F., Max, J.E., Frank, G.K., Paulus, M.P., Simmons, A.N., Gotlib, I.H., Yang, T.T., 2016. Large-Scale Hypoconnectivity Between Resting-State Functional Networks in Unmedicated Adolescent Major Depressive Disorder. Neuropsychopharmacol. doi:10.1038/npp.2016.76

Salomons, T.V., Dunlop, K., Kennedy, S.H., Flint, A., Geraci, J., Giacobbe, P., Downar, J., 2014. Resting-state cortico-thalamic-striatal connectivity predicts response to dorsomedial prefrontal rTMS in major depressive disorder.

Neuropsychopharmacol 39, 488-498. doi:10.1038/npp.2013.222

Schumann, G., Loth, E., Banaschewski, T., Barbot, A., Barker, G., Buechel, C., Conrod, P.J., Dalley, J.W., Flor, H., Gallinat, J., Garavan, H., Heinz, A., Itterman, B., Lathrop, M., Mallik, C., Mann, K., Martinot, J.-L., Paus, T., Poline, J.-B., Robbins, T.W., Rietschel, M., Reed, L., Smolka, M., Spanagel, R., Speiser, C., Stephens, D.N., Stroehle, A., Struve, M., IMAGEN Consortium, 2010. The IMAGEN study: reinforcement-related behaviour in normal brain function and psychopathology. Mol Psychiatr 15, 1128-1139. doi:10.1038/mp.2010.4

Shaffer, D., Fisher, P., Lucas, C.P., Dulcan, M.K., 2000. NIMH Diagnostic Interview Schedule for Children Version IV (NIMH DISC-IV): description, differences from previous versions, and reliability of some common diagnoses. J Am Acad Child Adolesc Psychiatry 39, 28-38. doi:10.1097/00004583-200001000-00014

Sheline, Y.I., Barch, D.M., Donnelly, J.M., Ollinger, J.M., Snyder, A.Z., Mintun, M.A., 2001. Increased amygdala response to masked emotional faces in depressed subjects resolves with antidepressant treatment: an fMRI study. Biol Psychiatry 50, 651-658. doi:10.1016/S0006-3223(01)01263-X

Smith, S.M., Jenkinson, M., Woolrich, M.W., Beckmann, C.F., Behrens, T.E.J., JohansenBerg, H., Bannister, P.R., De Luca, M., Drobnjak, I., Flitney, D.E., Niazy, R.K., 
Saunders, J., Vickers, J., Zhang, Y., De Stefano, N., Brady, J.M., Matthews, P.M., 2004. Advances in functional and structural MR image analysis and implementation as FSL. NeuroImage 23 Suppl 1, S208-19. doi:10.1016/j.neuroimage.2004.07.051

Straub, J., Plener, P.L., Sproeber, N., Sprenger, L., Koelch, M.G., Groen, G., Abler, B., 2015. Neural correlates of successful psychotherapy of depression in adolescents. J Affect Disord. doi:10.1016/j.jad.2015.05.020

Tahmasian, M., Knight, D.C., Manoliu, A., Schwerthöffer, D., Scherr, M., Meng, C., Shao, J., Peters, H., Doll, A., Khazaie, H., Drzezga, A., Bäuml, J., Zimmer, C., Förstl, H., Wohlschläger, A.M., Riedl, V., Sorg, C., 2013. Aberrant Intrinsic Connectivity of Hippocampus and Amygdala Overlap in the Fronto-Insular and DorsomedialPrefrontal Cortex in Major Depressive Disorder. Front Hum Neurosci 7, 639. doi:10.3389/fnhum.2013.00639

Tang, Y., Kong, L., Wu, F., Womer, F., Jiang, W., Cao, Y., Ren, L., Wang, J., Fan, G., Blumberg, H.P., Xu, K., Wang, F., 2013. Decreased functional connectivity between the amygdala and the left ventral prefrontal cortex in treatment-naive patients with major depressive disorder: a resting-state functional magnetic resonance imaging study. Psychol Med 43, 1921-1927. doi:10.1017/S0033291712002759

Tao, R., Calley, C.S., Hart, J., Mayes, T.L., Nakonezny, P.A., Lu, H., Kennard, B.D., Tamminga, C.A., Emslie, G.J., 2012. Brain activity in adolescent major depressive disorder before and after fluoxetine treatment. Am J Psychiatry 169, 381-388. doi:10.1176/appi.ajp.2011.11040615

Thompson, P.M., Andreassen, O.A., Arias-Vasquez, A., Bearden, C.E., Boedhoe, P.S., Brouwer, R.M., Buckner, R.L., Buitelaar, J.K., Bulayeva, K.B., Cannon, D.M., Cohen, R.A., Conrod, P.J., Dale, A.M., Deary, I.J., Dennis, E.L., de Reus, M.A., Desrivieres, S., Dima, D., Donohoe, G., Fisher, S.E., Fouche, J.-P., Francks, C., Frangou, S., Franke, B., Ganjgahi, H., Garavan, H., Glahn, D.C., Grabe, H.J., Guadalupe, T., Gutman, B.A., Hashimoto, R., Hibar, D.P., Holland, D., Hoogman, M., Pol, H.E.H., Hosten, N., Jahanshad, N., Kelly, S., Kochunov, P., Kremen, W.S., Lee, P.H., Mackey, S., Martin, N.G., Mazoyer, B., McDonald, C., Medland, S.E., Morey, R.A., Nichols, T.E., Paus, T., Pausova, Z., Schmaal, L., Schumann, G., Shen, L., Sisodiya, S.M., Smit, D.J.A., Smoller, J.W., Stein, D.J., Stein, J.L., Toro, R., Turner, J.A., van den Heuvel, M.P., van den Heuvel, O.L., van Erp, T.G.M., van Rooij, D., Veltman, D.J., Walter, H., Wang, Y., Wardlaw, J.M., Whelan, C.D., Wright, M.J., Ye, J., ENIGMA Consortium, 2015. ENIGMA and the individual: Predicting factors that affect the brain in 35 countries worldwide. NeuroImage. doi:10.1016/j.neuroimage.2015.11.057 Thompson, P.M., Stein, J.L., Medland, S.E., Hibar, D.P., Vasquez, A.A., Renteria, M.E., Toro, R., Jahanshad, N., Schumann, G., Franke, B., Wright, M.J., Martin, N.G., Agartz, I., Alda, M., Alhusaini, S., Almasy, L., Almeida, J., Alpert, K., Andreasen, N.C., Andreassen, O.A., Apostolova, L.G., Appel, K., Armstrong, N.J., Aribisala, B., Bastin, M.E., Bauer, M., Bearden, C.E., Bergmann, O., Binder, E.B., Blangero, J., Bockholt, H.J., Bøen, E., Bois, C., Boomsma, D.I., Booth, T., Bowman, I.J., Bralten, J., Brouwer, R.M., Brunner, H.G., Brohawn, D.G., Buckner, R.L., Buitelaar, J., Bulayeva, K., Bustillo, J.R., Calhoun, V.D., Cannon, D.M., Cantor, R.M., Carless, M.A., Caseras, X., Cavalleri, G.L., Chakravarty, M.M., Chang, K.D., Ching, C.R.K., 
Christoforou, A., Cichon, S., Clark, V.P., Conrod, P., Coppola, G., Crespo-Facorro, B., Curran, J.E., Czisch, M., Deary, I.J., de Geus, E.J.C., Braber, den, A., Delvecchio, G., Depondt, C., de Haan, L., de Zubicaray, G.I., Dima, D., Dimitrova, R., Djurovic, S., Dong, H., Donohoe, G., Duggirala, R., Dyer, T.D., Ehrlich, S., Ekman, C.J., Elvsåshagen, T., Emsell, L., Erk, S., Espeseth, T., Fagerness, J., Fears, S., Fedko, I., Fernández, G., Fisher, S.E., Foroud, T., Fox, P.T., Francks, C., Frangou, S., Frey, E.M., Frodl, T., Frouin, V., Garavan, H., Giddaluru, S., Glahn, D.C., Godlewska, B., Goldstein, R.Z., Gollub, R.L., Grabe, H.J., Grimm, O., Gruber, O., Guadalupe, T., Gur, R.E., Gur, R.C., Göring, H.H.H., Hagenaars, S., Hajek, T., Hall, G.B., Hall, J., Hardy, J., Hartman, C.A., Hass, J., Hatton, S.N., Haukvik, U.K., Hegenscheid, K., Heinz, A., Hickie, I.B., Ho, B.-C., Hoehn, D., Hoekstra, P.J., Hollinshead, M., Holmes, A.J., Homuth, G., Hoogman, M., Hong, L.E., Hosten, N., Hottenga, J.-J., Hulshoff Pol, H.E., Hwang, K.S., Jack, C.R., Jenkinson, M., Johnston, C., Jönsson, E.G., Kahn, R.S., Kasperaviciute, D., Kelly, S., Kim, S., Kochunov, P., Koenders, L., Krämer, B., Kwok, J.B.J., Lagopoulos, J., Laje, G., Landen, M., Landman, B.A., Lauriello, J., Lawrie, S.M., Lee, P.H., Le Hellard, S., Lemaître, H., Leonardo, C.D., Li, C.-S., Liberg, B., Liewald, D.C., Liu, X., Lopez, L.M., Loth, E., Lourdusamy, A., Luciano, M., Macciardi, F., Machielsen, M.W.J., MacQueen, G.M., Malt, U.F., Mandl, R., Manoach, D.S., Martinot, J.-L., Matarin, M., Mather, K.A., Mattheisen, M., Mattingsdal, M., MeyerLindenberg, A., McDonald, C., McIntosh, A.M., McMahon, F.J., McMahon, K.L., Meisenzahl, E., Melle, I., Milaneschi, Y., Mohnke, S., Montgomery, G.W., Morris, D.W., Moses, E.K., Mueller, B.A., Muñoz Maniega, S., Mühleisen, T.W., MüllerMyhsok, B., Mwangi, B., Nauck, M., Nho, K., Nichols, T.E., Nilsson, L.-G., Nugent, A.C., Nyberg, L., Olvera, R.L., Oosterlaan, J., Ophoff, R.A., Pandolfo, M., Papalampropoulou-Tsiridou, M., Papmeyer, M., Paus, T., Pausova, Z., Pearlson, G.D., Penninx, B.W., Peterson, C.P., Pfennig, A., Phillips, M.L., Pike, G.B., Poline, J.B., Potkin, S.G., Pütz, B., Ramasamy, A., Rasmussen, J., Rietschel, M., Rijpkema, M., Risacher, S.L., Roffman, J.L., Roiz-Santiañez, R., Romanczuk-Seiferth, N., Rose, E.J., Royle, N.A., Rujescu, D., Ryten, M., Sachdev, P.S., Salami, A., Satterthwaite, T.D., Savitz, J., Saykin, A.J., Scanlon, C., Schmaal, L., Schnack, H.G., Schork, A.J., Schulz, S.C., Schür, R., Seidman, L., Shen, L., Shoemaker, J.M., Simmons, A., Sisodiya, S.M., Smith, C., Smoller, J.W., Soares, J.C., Sponheim, S.R., Sprooten, E., Starr, J.M., Steen, V.M., Strakowski, S., Strike, L., Sussmann, J., Sämann, P.G., Teumer, A., Toga, A.W., Tordesillas-Gutiérrez, D., Trabzuni, D., Trost, S., Turner, J., Van den Heuvel, M., van der Wee, N.J., van Eijk, K., van Erp, T.G.M., van Haren, N.E.M., van 't Ent, D., van Tol, M.-J., Valdés Hernández, M.C., Veltman, D.J., Versace, A., Völzke, H., Walker, R., Walter, H., Wang, L., Wardlaw, J.M., Weale, M.E., Weiner, M.W., Wen, W., Westlye, L.T., Whalley, H.C., Whelan, C.D., White, T., Winkler, A.M., Wittfeld, K., Woldehawariat, G., Wolf, C., Zilles, D., Zwiers, M.P., Thalamuthu, A., Schofield, P.R., Freimer, N.B., Lawrence, N.S., Drevets, W.C., Alzheimer's Disease Neuroimaging Initiative, EPIGEN Consortium, IMAGEN Consortium, Saguenay Youth Study (SYS) Group, 2014. The ENIGMA Consortium: large-scale collaborative analyses of neuroimaging and genetic data. Brain Imaging Behav 8, 153-182. doi:10.1007/s11682-013-9269-5

Urry, H.L., van Reekum, C.M., Johnstone, T., Kalin, N.H., Thurow, M.E., Schaefer, H.S., Jackson, C.A., Frye, C.J., Greischar, L.L., Alexander, A.L., Davidson, R.J., 2006. 
Amygdala and ventromedial prefrontal cortex are inversely coupled during regulation of negative affect and predict the diurnal pattern of cortisol secretion among older adults. J Neurosci 26, 4415-4425. doi:10.1523/JNEUROSCI.321505.2006

Veer, I.M., Beckmann, C.F., van Tol, M.-J., Ferrarini, L., Milles, J., Veltman, D.J., Aleman, A., van Buchem, M.A., van der Wee, N.J., Rombouts, S.A.R.B., 2010. Whole brain resting-state analysis reveals decreased functional connectivity in major depression. Front Sys Neurosci 4. doi:10.3389/fnsys.2010.00041

Wechsler, D., 1999. Wechsler Abbreviated Scale of Intelligence Administration and Scoring Manual. The Psychological Corporation, San Antonio.

Yang, T.T., Simmons, A.N., Matthews, S.C., Tapert, S.F., Frank, G.K., Max, J.E., BischoffGrethe, A., Lansing, A.E., Brown, G., Strigo, I.A., Wu, J., Paulus, M.P., 2010. Adolescents with major depression demonstrate increased amygdala activation. J Am Acad Child Adolesc Psychiatry 49, 42-51. doi:10.1016/j.jaac.2009.09.004

Zhang, Y., Brady, M., Smith, S.M., 2001. Segmentation of brain MR images through a hidden Markov random field model and the expectation-maximization algorithm. IEEE T Med Imaging 20, 45-57. doi:10.1109/42.906424

Zhu, X., Wang, X., Xiao, J., Liao, J., Zhong, M., Wang, W., Yao, S., 2012. Evidence of a Dissociation Pattern in Resting-State Default Mode Network Connectivity in First-Episode, Treatment-Naive Major Depression Patients. Biol Psychiatry 71, 611-617. 
A. Left Amygdala Seed
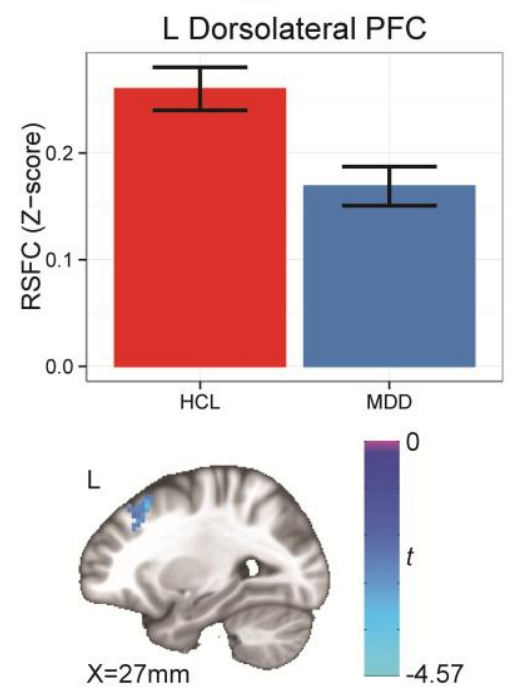

B. Right Amygdala Seed
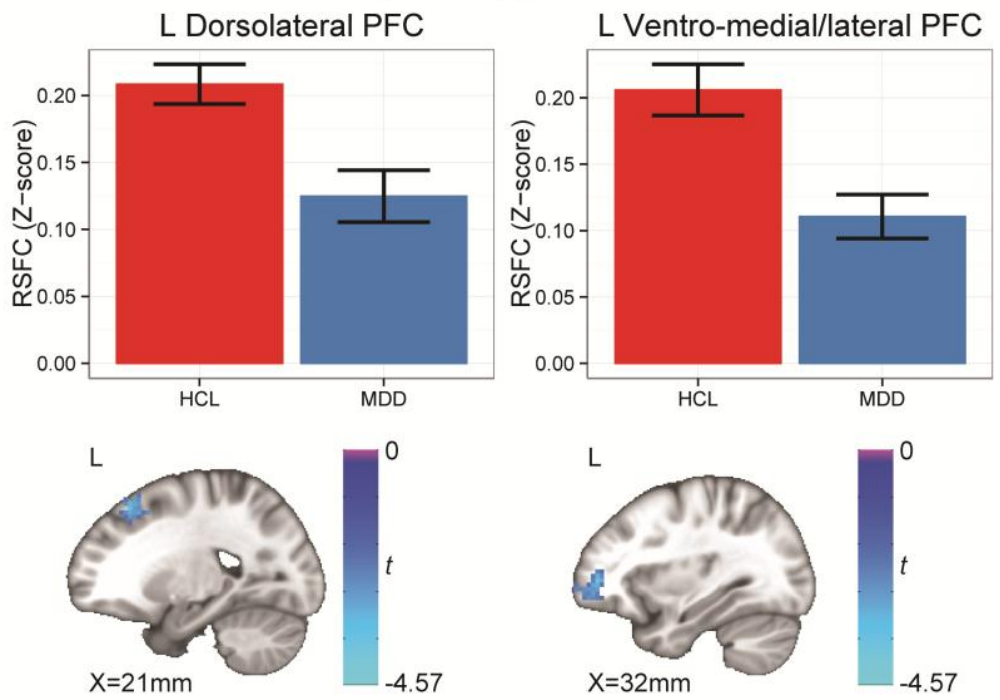
Right Amygdala Seed

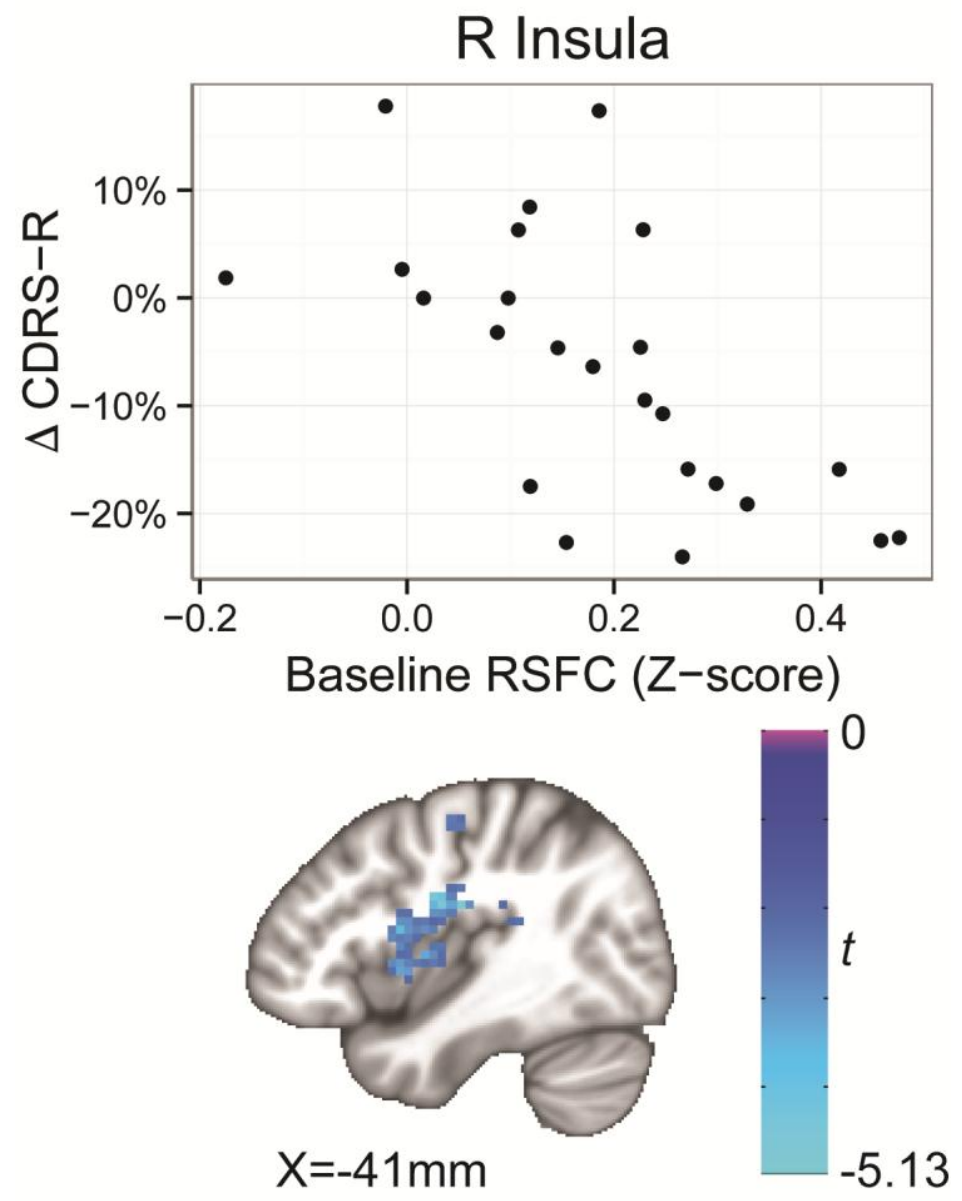


Table 1. Participant demographic and clinical characteristics.

\begin{tabular}{|c|c|c|c|c|}
\hline Characteristic & MDD $^{a}$ & $\mathrm{HCL}^{\mathrm{a}}$ & Statistic ${ }^{b, c}$ & $p$ \\
\hline Participants recruited & 66 & 77 & $\chi^{2}(1)=0.70$ & 0.40 \\
\hline $\begin{array}{l}\text { Participants dropped because of excessive } \\
\text { motion }\end{array}$ & 18 & 24 & $\chi^{2}(1)=0.60$ & 0.44 \\
\hline Participants in final analysis & 48 & 53 & $\chi^{2}(1)=0.16$ & 0.69 \\
\hline Gender (M/F) & $19 / 29$ & $20 / 33$ & $\chi^{2}(1)=0.00$ & 1.00 \\
\hline Age at scan (years) & $16.1 \pm 1.3$ & $16.1 \pm 1.3$ & $\begin{array}{l}t(97.08)=- \\
0.08\end{array}$ & 0.93 \\
\hline Hollingshead Socioeconomic Score $†$ & $35 \pm 37.5$ & $\begin{array}{l}29 \pm 36.2 \\
{[1]}\end{array}$ & $W=1392$ & 0.32 \\
\hline Tanner Score ${ }^{\dagger}$ & $4 \pm 0.5$ & $4 \pm 1$ & $W=1432$ & 0.25 \\
\hline Wechsler Abbreviated Scale of & $100.2 \pm$ & $109.8 \pm$ & $t(98.87)=-$ & $<0.0$ \\
\hline Intelligence (Full) & 11.6 & 12.4 & 3.99 & 01 \\
\hline Children's Global Assessment Scale & $64.2 \pm 12$ & $90.9 \pm 5.7$ & $\begin{array}{l}t(66.00)=- \\
14.02\end{array}$ & $\begin{array}{r}<0.0 \\
01\end{array}$ \\
\hline Children's Depression Rating Scale ${ }^{\mathrm{d}}$ & $70.2 \pm 9.5$ & $32.8 \pm 4$ & $\begin{array}{l}t(61.68)=25 \\
.28\end{array}$ & $\begin{array}{r}<0.0 \\
01\end{array}$ \\
\hline $\begin{array}{l}\text { Reynolds Adolescent Depression Scale } \\
\text { Total }^{d}\end{array}$ & $64.7 \pm 9.2$ & $\begin{array}{l}40.8 \pm 7.4 \\
{[1]}\end{array}$ & $\begin{array}{l}t(90.11)=14 \\
.24\end{array}$ & $\begin{array}{r}<0.0 \\
01\end{array}$ \\
\hline $\begin{array}{l}\text { Multidimensional Anxiety Scale for } \\
\text { Children }{ }^{\mathrm{d}}\end{array}$ & $\begin{array}{l}58 \pm 8.9 \\
{[3]}\end{array}$ & $\begin{array}{l}42.1 \pm 8.4 \\
{[1]}\end{array}$ & $\begin{array}{l}\mathrm{t}(91.24)=9 \\
03\end{array}$ & $\begin{array}{r}<0.0 \\
01\end{array}$ \\
\hline \multicolumn{5}{|l|}{ Children's Depression Rating Scale ${ }^{d}$} \\
\hline Participants in analysis & 24 & 11 & & \\
\hline Days between assessments & $\begin{array}{l}99.8 \pm \\
19.6[1]\end{array}$ & $\begin{array}{l}109 \pm \\
22.9\end{array}$ & $\begin{array}{l}t(17.28)=- \\
1.15\end{array}$ & 0.27 \\
\hline $\begin{array}{l}\text { Difference in CDRS-R from baseline to } \\
\text { follow-up }\end{array}$ & $-4.7 \pm 9.2$ & $2.1 \pm 8.0$ & $\begin{array}{l}F(1, \\
33)=4.41\end{array}$ & $\begin{array}{r}<0.0 \\
5\end{array}$ \\
\hline Baseline & $\begin{array}{l}68.3 \pm \\
10.0\end{array}$ & $32.5 \pm 2.9$ & & \\
\hline Three months follow-up & $\begin{array}{l}63.6 \pm \\
11.4\end{array}$ & $34.6 \pm 7.6$ & & \\
\hline \multicolumn{5}{|l|}{ Comorbid Diagnoses in the MDD Group } \\
\hline No comorbid diagnoses ${ }^{e}$ & 29 & & & \\
\hline $\begin{array}{l}\text { Generalized Anxiety Disorder } \\
\text { (Current/Past) }\end{array}$ & $12 / 11$ & & & \\
\hline Specific Phobia (Current/Past) & $4 / 4$ & & & \\
\hline $\begin{array}{l}\text { Anxiety Disorder Not Otherwise Specified } \\
\text { (Current/Past) }\end{array}$ & $1 / 1$ & & & \\
\hline $\begin{array}{l}\text { Post-Traumatic Stress Disorder } \\
\text { (Current/Past) }\end{array}$ & $5 / 3$ & & & \\
\hline
\end{tabular}


${ }^{\text {a Mean }} \pm$ SD or median \pm IQR if indicated by + . [] indicated the number of missing data points.

${ }^{b}$ Statistic: W, Wilcox rank sum test; $\chi^{2}, \chi^{2}$ test for equality of proportions; $t$, Student's T test.

c Statistics for clinical scales refer only to participants included in the final analysis.

d Standardized

e The KSADS data for 4 participants was mislaid after diagnosis. Consequently, no comorbidity information is available for those participants.

Abbreviations: $\mathrm{Cl}$, Confidence Interval; SD, standard deviation; IQR, interquartile range; $M$, male; $F$, female. 
Table 2. Brain regions showing between group differences in the resting-state functional connectivity of the amygdala seeds.

\begin{tabular}{|c|c|c|c|c|c|c|c|c|c|}
\hline \multirow[t]{2}{*}{ Structure } & \multirow[t]{2}{*}{$\begin{array}{c}\text { Sid } \\
\text { e }\end{array}$} & \multirow[t]{2}{*}{$\begin{array}{c}\text { Volum } \\
\text { e } \mu \mathrm{L}\end{array}$} & \multicolumn{3}{|c|}{$\begin{array}{l}\text { Center of } \\
\text { Mass }\end{array}$} & \multirow{2}{*}{$\begin{array}{c}\text { Averag } \\
\text { e t- } \\
\text { value a }^{\text {a }}\end{array}$} & \multirow{2}{*}{$\begin{array}{c}\text { Averag } \\
\text { e } \\
\text { Contras } \\
\text { t Value }\end{array}$} & \multicolumn{2}{|c|}{$\begin{array}{l}\text { Mean } \\
\text { RSFC }\end{array}$} \\
\hline & & & $x$ & $\mathbf{Y}$ & $\mathbf{Z}$ & & & $\begin{array}{c}\text { MD } \\
\mathrm{D}\end{array}$ & NCL \\
\hline \multicolumn{10}{|l|}{ Left Amygdala Seed } \\
\hline Lingual Gyrus & $\mathrm{L}$ & 46,116 & 12 & 80 & -14 & -2.39 & -0.12 & 0.14 & $\begin{array}{r}0.2 \\
3\end{array}$ \\
\hline $\begin{array}{l}\text { Superior Temporal } \\
\text { Gyrus }\end{array}$ & $\mathrm{L}$ & 9,693 & 51 & 7 & -8 & -2.40 & -0.13 & 0.20 & $\begin{array}{r}0.3 \\
0\end{array}$ \\
\hline Precuneus & $\mathrm{R}$ & 6,237 & -26 & 65 & 20 & -2.38 & -0.09 & 0.09 & $\begin{array}{r}0.1 \\
6\end{array}$ \\
\hline Superior Frontal Gyrus & $\mathrm{L}$ & 5,454 & 23 & -24 & 50 & -2.35 & -0.10 & 0.17 & $\begin{array}{r}0.2 \\
6\end{array}$ \\
\hline \multicolumn{10}{|l|}{ Right Amygdala Seed } \\
\hline Precuneus & $\mathrm{L}$ & 42,606 & 0 & 55 & 51 & -2.47 & -0.11 & 0.15 & $\begin{array}{r}0.2 \\
5\end{array}$ \\
\hline Lingual Gyrus & $\mathrm{L}$ & 16,524 & 15 & 84 & -14 & -2.35 & -0.11 & 0.15 & $\begin{array}{r}0.2 \\
3\end{array}$ \\
\hline Superior Frontal Gyrus & $\mathrm{L}$ & 12,258 & 10 & -60 & 1 & -2.41 & -0.11 & 0.11 & $\begin{array}{r}0.2 \\
1\end{array}$ \\
\hline Inferior Occipital Gyrus & $\mathrm{R}$ & 6,723 & -32 & 84 & -9 & -2.39 & -0.11 & 0.14 & $\begin{array}{r}0.2 \\
4\end{array}$ \\
\hline Superior Frontal Gyrus & $\mathrm{L}$ & 5,211 & 22 & -22 & 52 & -2.39 & -0.09 & 0.12 & $\begin{array}{r}0.2 \\
1\end{array}$ \\
\hline
\end{tabular}

Center-of-mass coordinates are in radiological convention and structure labels are from the Talairach \& Tournoux atlas. L, Left; R, Right. ${ }^{a}$ t(21) 
Table 3. Brain regions showing a relationship between baseline resting-state functional connectivity of the amygdala and difference in CDRS-R score from baseline to three months follow-up.

\begin{tabular}{|c|c|c|c|c|c|c|c|c|c|}
\hline \multirow[t]{2}{*}{ Structure } & \multirow[t]{2}{*}{$\begin{array}{c}\text { Sid } \\
\text { e }\end{array}$} & \multirow[t]{2}{*}{$\begin{array}{c}\text { Volum } \\
\text { e } \mu \mathrm{L}\end{array}$} & \multicolumn{3}{|c|}{$\begin{array}{c}\text { Center of } \\
\text { Mass }\end{array}$} & \multirow{2}{*}{$\begin{array}{c}\text { Averag } \\
\text { e t- } \\
\text { value }^{a}\end{array}$} & \multirow{2}{*}{$\begin{array}{c}\text { Averag } \\
\text { e } \beta \\
\text { Value }\end{array}$} & \multirow[t]{2}{*}{$\begin{array}{c}\text { Averag } \\
\text { e Bias }\end{array}$} & \multirow{2}{*}{$\begin{array}{c}\text { Mea } \\
n \\
\text { RSFC }\end{array}$} \\
\hline & & & $x$ & $\mathbf{Y}$ & $\mathbf{Z}$ & & & & \\
\hline \multicolumn{10}{|c|}{ Left Amygdala Seed } \\
\hline Cul & $\mathrm{R}$ & 10,638 & -8 & 38 & $\begin{array}{r}- \\
36\end{array}$ & -2.89 & -0.29 & 0.0001 & 0.15 \\
\hline
\end{tabular}

Right Amygdala

Seed

$\begin{array}{llllllllll}\text { Insula/Postcentral } & R & 19,818 & - & 11 & 20 & -2.7 & -0.28 & 0.0013 & 0.19\end{array}$

Gyrus

48

Center-of-mass coordinates are in radiological convention and structure labels are from the Talairach \& Tournoux atlas. L, Left; R, Right. ${ }^{a}$ t(21) 